\title{
Estudo de Infiltração para verificar a presença de Recalque através do GPR
}

\author{
Gleide Alencar do Nascimento Dias ${ }^{1}$; Marcelo Cabral dos Santos Junior ${ }^{2}$ \\ ${ }^{1,2}$ Departamento de Geologia/ Universidade Federal do Rio de Janeiro - UFRJ
}

Copyright 2016, SBGf - Sociedade Brasileira de Geofísica

Este texto foi preparado para a apresentação no VII Simpósio Brasileiro de Geofísica, Ouro Preto, 25 a 27 de outubro de 2016. Seu conteúdo foi revisado pelo Comitê Técnico do VII SimBGf, mas não necessariamente representa a opinião da SBGf ou de seus associados. É proibida a reprodução total ou parcial deste material para propósitos comerciais sem prévia autorização da SBGf.

\section{Resumo}

O método geofísico Radar de Penetração em Solo (GPR) foi utilizado nesse estudo para verificar a presença de água ou cavidades no solo devido a presença de fissuras no $3^{\circ}$ andar de um prédio de 3 andares (recalque). A área estudada localiza-se na Ilha do Fundão no Rio de Janeiro e se trata de uma sala de um prédio do Departamento de Geologia da Universidade Federal do Rio de Janeiro. Foram adquiridos 10 perfis paralelos como um aparelho do modelo TerraSIRch SIR System-3000, em um frequência de $200 \mathrm{MHz}$. Na sala em que o método foi utilizado foi verificado que contato aterro-solo está em torno de 2 a $3 \mathrm{~m}$ de profundidade. $\mathrm{E}$ a que a infiltração presente vai até $60 \mathrm{~cm}$ de profundidade em certo trecho da sala estudada. Não foi verificada a presença de estruturas que podem influenciar o recalque do prédio.

\section{Introdução}

Esse trabalho teve por motivação estudar o caso de fissuras e rachaduras nas paredes de uma das salas do Departamento de Geologia e que podiam terem sido geradas por recalque da fundação. Recalque pode ser definido como o movimento da fundação de uma construção causado pela mudança espacial ou deformação do solo (Santos, 2014).

$O$ recalque pode ser simplesmente um recalque absoluto, que é o deslocamento vertical de um elemento da fundação; um recalque diferencial, que é a diferença dos recalques absolutos em dois pontos diferentes; e o recalque diferencial específico que é a distorção angular, calculada fundamentalmente pela razão do recalque diferencial pela distância entre os pontos de deslocamento absoluto. Podemos classificar os tipos de recalque absoluto pelo o que ocorre com o solo no evento (Santos, 2014).

O recalque elástico ocorre imediatamente após a aplicação da carga e são maiores em solos não coesivos, ou seja, em solos não argilosos. Também denominado recalque imediato, deve-se considerar a rigidez da fundação, sua forma, profundidade e a espessura da camada deformável de solo.

O recalque por escoamento lateral $A$ deformação por escoamento lateral acontece com maior predominância em solos não coesivos. Trata-se da migração de solo de regiões mais solicitadas para as menos solicitadas, ou seja, o deslocamento se dá do centro para a lateral. Verificam-se de maneira mais acentuada nos solos não coesivos sob fundações superficiais.

A deformação por adensamento ocorre pela diminuição no volume aparente do maciço de solo, causada pelo fechamento dos vazios deixados pela água expulsa em função da pressão da fundação aplicada ao solo.

E segundo outros textos, ainda há o recalque de compressão secundária que é devido ao rearranjo estrutural do solo por causa das forças de cisalhamento forças opostas sendo aplicadas em pontos diferentes provocando movimentos contrários em relação a um plano. Ocorre lentamente em solos argilosos e geralmente é desprezado no cálculo de fundação. (Fabrício and Rossignolo, 2003).

Segundo Barraca (2016) o uso do GPR por ser um método geofísico não-destrutivo, não-invasivo e além de produzir uma ampla gama de informações cruciais de informações são importantes a serem usados por engenheiros e arquitetos, levando a intervenções de engenharia adequadas, capazes de garantir a integridade estrutural de construção e preservação de elementos arquitetônicos. Os problemas encontrados e as condições de pesquisa abordam uma situação modelo de investigação e, portanto, a discussão e resultados, tais como a escolha da antena, particularidades de processamento de dados, pode ser estendido para outros casos e utilizado como uma orientação para obras. 


\section{Metodologia/ Problema Investigado}

O método GPR (Ground Penetrating Radar) se baseia na emissão e captação de ondas eletromagnéticas de freqüências entre $10 \mathrm{MHz}$ e 2,5 $\mathrm{GHz}$. Quando o pulso eletromagnético alcança uma superfície de separação entre solos ou materiais com propriedades eletromagnéticas muito diferentes, uma parte da onda sofre reflexão e difração e a outra parte da onda continua se propagando até ser totalmente absorvida pelo solo. Essa porção da onda que foi refletida e retorna a antena é que detecta em pulsos, o esse é enviado para uma unidade de controle, onde os sinais são amplificados e guardados em uma unidade de processamento de dados. As representações dos scans fornece o radargrama que mostra uma seção $2 \mathrm{D}$ (bidimensional) do solo.

$\mathrm{Na}$ área de engenharia e construção civil esse equipamento pode ser aplicado na avaliação de rodovias públicas (asfalto), na deterioração de decks de pontes e revestimentos de túneis para localizar barras de ferro a fim diagnosticar a corrosão, nível do lençol freático e argila. Pode ser usado também no estudo de rachaduras dentro de pavimentos com objetivo de estimar a profundidade delas e encontrar fissuras escondidas (Birtwisle and Utsi, 2008).

\section{Geologia do Local}

A llha do Fundão é ocupada em sua maior parte pela Cidade Universitária e é uma das muitas ilhas da Baía de Guanabara e e se localiza entre as coordenadas latitudinais 22 $49^{\prime} 55^{\prime \prime} S-22^{\circ} 53^{\prime} 10^{\prime \prime S}$ e longitudinais $43^{\circ} 12^{\prime} 25^{\prime \prime} \mathrm{W}-43^{\circ} 14^{\prime} 45^{\prime} \mathrm{W}$ (Figura 1). Segundo Amador (1996), possui $377 \mathrm{Km}^{2}$, excluindo as ilhas e considerando seu limite pelas pontas de Copacabana e de Itaipu. A Ilha do Fundão foi criada apartir do aterro dos canais entre noves ilhas (Cabras, Pindaí do Ferreira, Pindaí do França, Baiacu, Fundão, Catalão, Bom Jesus, Pinheiro e Sapucaia), localizadas no Estuário de Manguinhos, na Enseada de Inhaúma.

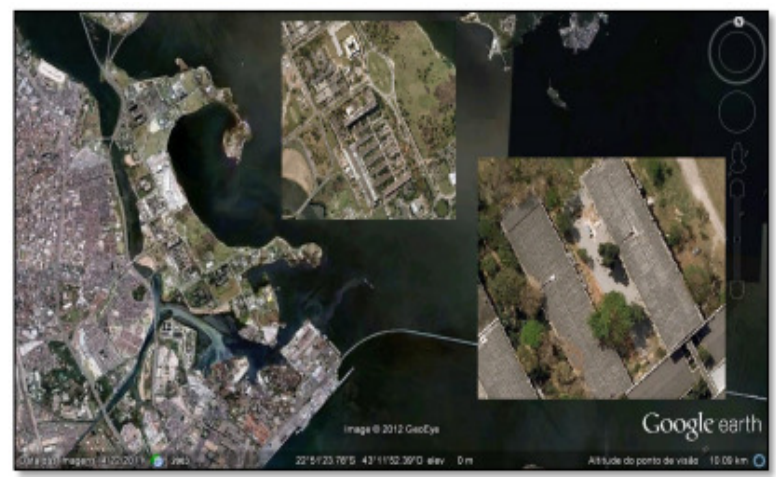

Figura 1 - Localização da área de estudo. Fonte: Google Earth.
O solo dessas ilhas é constituído predominantemente por gnaisses variados e migmatitos, da idade Pré-Cambriana. Os aterros são constituídos de areias dragadas da Baia de Guanabara e solos de alteração de Gnaisses e migmatitos do desmonte da Colina do Fundão. De acordo com Santos (2000), na llha do Fundão foram mapeados e descritos cinco tipos de solos classificados de acordo com a avaliação do grau de fertilidade das amostras de aterros e/ou solos coletadas. Os cinco tipos são aterro solódico ou não (AT1), aterro com calhaus a $20 \mathrm{~cm}$ (AT2), aterro com calhaus a $60 \mathrm{~cm}$ ou $80 \mathrm{~cm}$ (AT3), aterro gleizado (AT4) e Argissolo Vermelho-Amarelo eutrófico abrúptico (PVAe) (Figura 2).

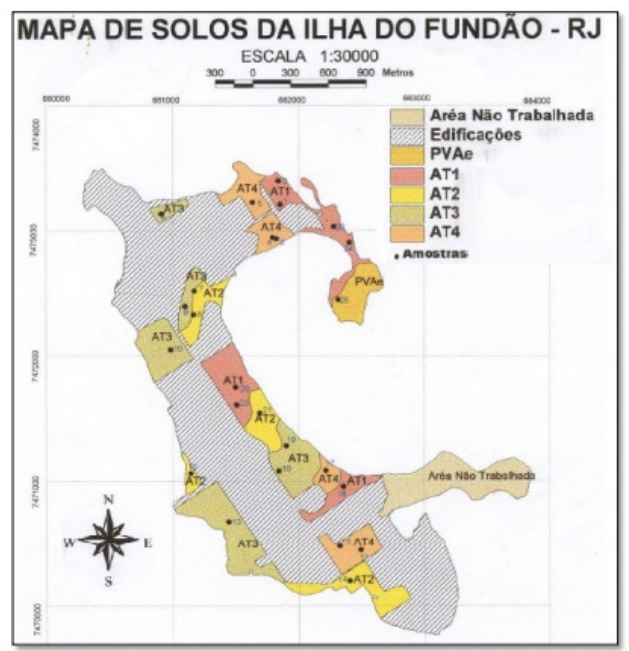

Figura 2 - Mapa de distribuição dos solos baseada na avaliação da fertilidade (Santo, 2000).

Em Dias et al (2013) nas seções radargramas próximas a área é possível observar um forte refletor horizontal contínuo, situado a aproximadamente $3,80 \mathrm{~m}$ de profundidade ( $80 \mathrm{~ns}$ ), que corresponde ao contato aterro-solo. Um indicativo a ser esperado para a outra área de estudo. O local de estudo possui uma área de aproximadamente $8,85 \mathrm{~m} \times 5,80 \mathrm{~m}$, dentro da sala J0-011 do departamento de Geologia (Figura 3). Dentro da sala é possível verificar a presença de infiltrações como mostrado.

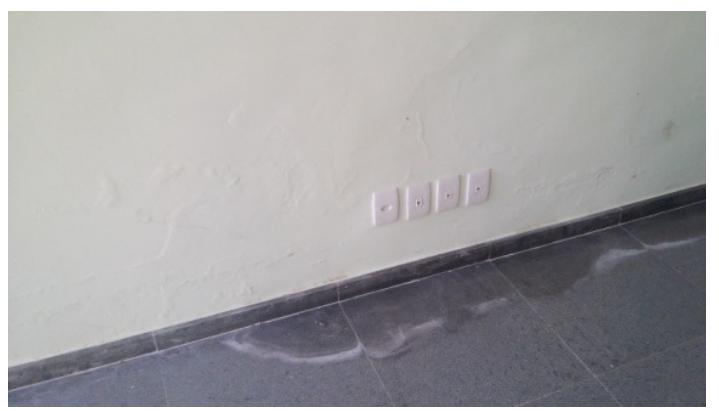

Figura 3 - Presença de infiltrações dentro da sala J0-011. 


\section{Aquisição de Dados}

O sistema de aquisições de dados do GPR depende do equipamento que está sendo usado, por isso é preciso abordar genericamente esse assunto. Todos equipamentos GPR possuem uma Unidade Controle Central ou console associado a um equipamento para o armazenamento de dados ou um notebook para a visualização e pré-processamento de dados brutos; e um sistema de antenas com uma antena - monoestático, ou com duas antenas, sendo uma emissora e outra receptora de ondas - biestático. Durante a aquisição de dados o console é ligado às antenas por fios ópticos para que há interferências nos dados, os dados são sincronizados no sistema de antenas e converte o sinal analógico em digital para o armazenamento no computador.

Segundo Annan (1992), é preciso ter cinco informações bem claras para iniciar o processo de aquisição: verificar a profundidade de estudo, pois cada antena possui um alcance; a geometria e o tamanho do objeto, além da sua orientação caso ele não seja esférico; as propriedades elétricas do objeto, pois ele não será detectado pelo radar se ele tiver propriedades semelhantes ao solo; a classificação do material encaixante usando a condutividade elétrica e a permissividade relativa deste para estimar o grau e a escala espacial da heterogeneidade nas propriedades elétricas do encaixante através do quadrado do módulo dos coeficientes de reflexão do GPR; e as interferências do meio como fontes emissoras de ondas de radio e corpos metálicos refletores.

Nesse estudo foram adquiridos 10 perfis com o equipamento geofísico GPR do modelo TerraSIRch SIR System-3000 com antena monoestática de frequência de 200 Mhz (Figura 4). Todas os 10 perfis foram obtidos paralelamente com direção N45E com espaçamento entre as linhas de $58 \mathrm{~cm}$ (Figura 5). Os parâmetros de foram obtidos de acordo com o proposto pelo manual: Antena de transmissão $200 \mathrm{MHz}$, Modo de aquisição Pontual, Amostragem por Scan 512, resolução 16 bits, Range, 100 ns, Permissividade 9, Scan por unidade 60 .

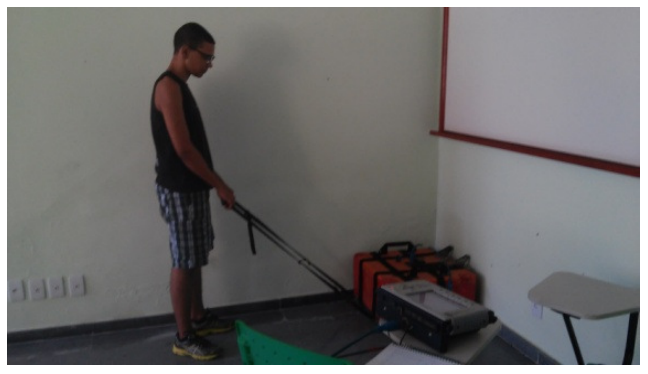

Figura 4 - Foto do equipamento sendo utilizado na sala J0-011.

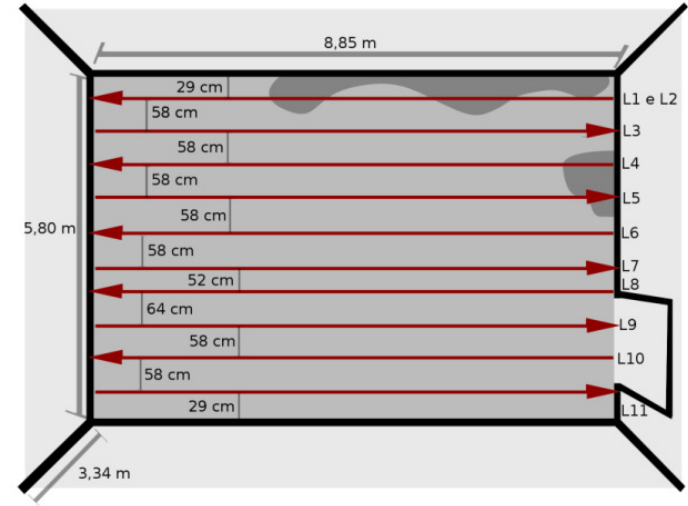

Figura 5 - Geometria de aquisição dos perfis.

\section{Processamento de Dados}

O processamento de dados é importante para melhorar a nitidez e amplificar pontos importantes nos dados. Há dois tipos de processamento: o Básico durante a aquisição através da pré-visualização - e o Avançado - depois da aquisição no escritório. O Básico é composto pela Edição, Geometria, Filtragem DC, Ganho, Filtros Espaciais e Temporais. O Avançado é composto por Deconvolução, Subtração do Background, Filtros FK, Análise de Velocidades, Correção NMO, Correções Estáticas Residuais e etc

Após serem realizadas as aquisições dos dados,esse foram processados no software REFLEXW, versão 4.2 da empresa Sandmeier, segui-se as seguintes etapas no processamento a partir do dado bruto para filtrar ruídos e realçar objetos de estudo relevantes:a) Static Correction / muting > Move StartTime. b) 1D-filter > Subtract-mean (dewow). c) $2 D$-filter > Background Removal. d) 1D-filter > Bandpass frequency. 2D-filter > Background Removal. e) Gain > Div. Compensation. F)Trace Interpolation/Resorting $>$ XflipProfile

\section{Resultados e interpretação de dados}

Para interpretar os dados é preciso manter em mente o objeto a ser estudado, o modelo geológico, verificar as duas reflexões fortes diretas no início do perfil sendo uma no ar e outra na terra e identificar e diferenciar as origens dos sinais que representam o objeto de estudo e as interferências indesejadas.

No radargrama, as hipérboles fechadas representam refletores enterrados como canos e tanques; e as hipérboles abertas são refletores na superfície como paredes e postes. Formas contínuas horizontais são resultantes de superfícies contínuas como mudança de solos com propriedades eletromagnéticas diferentes. Além disso, é preciso saber identificar traços de influências externas: objetos na superfície como árvores de grande porte, objetos sobre a cabeça como torres de alta tensão e transmissores de sinais EM como sinais de rádio FM. Em estudos com o 
método GPR para tubulações são verificados que a presença dessas são feitas através da presença de ondas difratadas caracterizadas por uma hipérbole e com respectivo valor de velocidade, como em Pinto (2010).

Nesse estudo os objetivos foram investigar as condições geológicas locais, ou seja, camadas, lençol freático, camadas antrópicas e quaisquer outras informações relevantes para alteração da caracterização das fundações de edifícios e infra-estruturas. O prédio foi tem edifício é construído em sedimentos recentes, perto de uma ribeira de idade.

$\mathrm{Na}$ Figura 6 são apresentadas somente duas seções radargramas dos 10 perfis adquiridos, os demais não foram apresentados por apresentarem mesma semelhança estrutural, nessas seções são verificadas a presença em torno de 2 a $3 \mathrm{~m}$ o contato aterro-solo, cuja deposição apresenta-se acima da linha em vermelho são plano paralelas (aterro) provavelmente de ação antrópica para a construção do piso da sala e abaixo dela a presença de estruturas com camadas de baixa inclinação
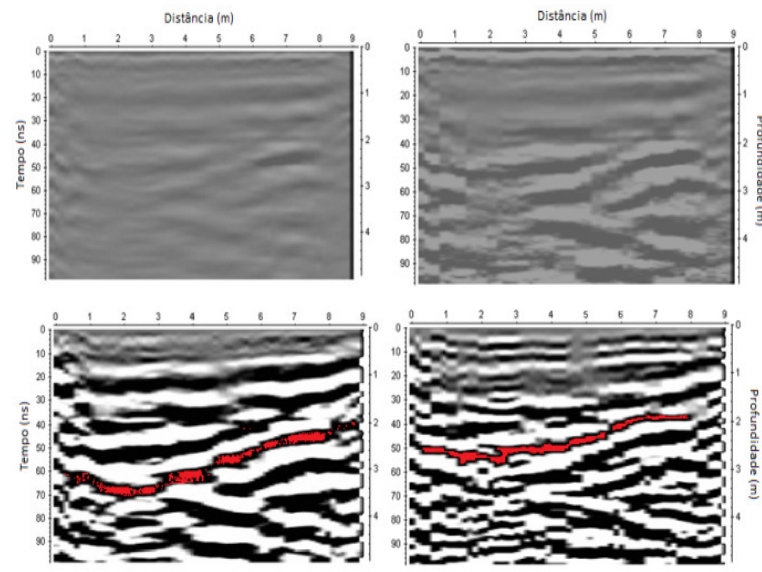

Figura 6 - Seção radargrama sem processamento acima e abaixo seções radargramas processadas.

As seções radargramas podem ser visualizadas variando os perfis em 2D (de separação entre os perfis) ou em profundidade a partir de uma seção 3D (tridimensional) (Figura 7). A marcação em vermelho na figura representa a entrada da porta a sala J0-011.

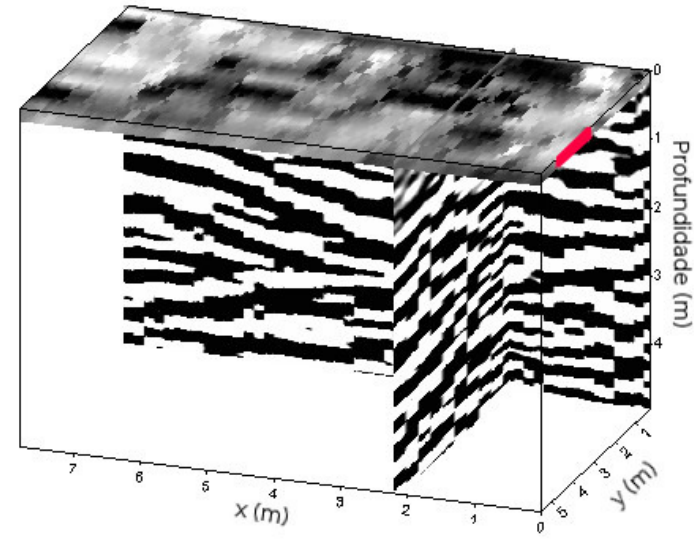

Figura 7 - Seção radargrama processada com seções em 2D compondo o modelo 3D.

Em análise a presença de água no solo (inflitração) em profundidade, os perfis dispostos em seção 3D, cuja as seções foram verificadas de10 em 10 $\mathrm{cm}$ de profundidade. Nessa análise como mostrado na Figura 8 a inflitração está bem próxima a parede e chega a $50 \mathrm{~cm}$ de profundidade mostrando que a inflitração pode estar relacionada ao vazamento de uma tubulação e não a presence de lençol freático. Essa infiltração pode ser visualizada nas 5 primeiras seções de cima para baixo da figura, em rosa claro e amarelo.

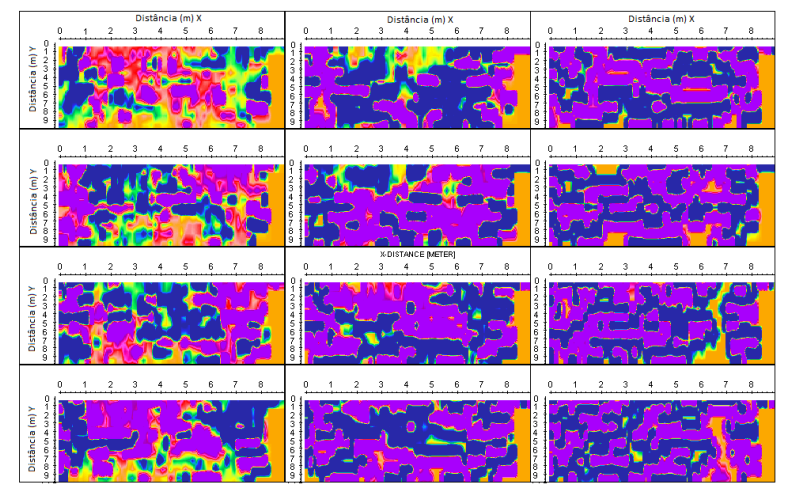

Figura 8 - Seção radargrama 3D visualizada em profundidade.

Nas seções não foram identificadas cavidades que poderiam estar associadas a causa do surgimento de fraturas e fissuras na sala J0-011.

\section{Conclusão}

O uso de GPR em engenharia vem a colaborar no estudo de estruturas que podem ser afetadas pela a geologia do meio, contribuindo na redução de custos em projetos de engenharia, Seria recomendado que fossem realizadas mais estudos com o GPR em outras salas 
próximas a viga de construção da sala J0-011, de forma a ser integrado a esses resultados. As respostas das seções radargramas não mostram a presença de cavidades somente à presença de infiltrações que vão até aproximadamente $50 \mathrm{~cm}$ de profundidade.

\section{Agradecimentos}

Ao Laboratório de Física do Departamento de Geologia da UFRJ.

\section{Referências}

A. Birtwisle and E. Utsi. 2008. The use of ground penetrating radar to detect vertical subsurface cracking in airport runways. Proceedings of the 12th International Conference on Ground Penetrating Radar (GPR2008).

Barraca N., Almeida M, Varum H, Fernando Almeida F. and Matias M. S. 2016. A case study of the use of GPR for rehabilitation of a classified Art Deco building: The InovaDomus house. Journal of Applied Geophysics.V.127, April, Pages 1-13

Dias G. A. N. , Delboni J. R., and Mansur J. W. 2013. The use of multiple low frequency (MLF) for the GPR method in the test area of fundão island correlated to wells electric profiles. 13th International Congress of the Brazilian Geophysical Society \& EXPOGEF, Rio de Janeiro, Brazil, 26-29 August 2013: pp. 808-814. doi: 10.1190/sbgf2013-166

Fabrício, M.M. and Rossignolo, J. A. 2015. Recalques de Fundações Diretas. Fundações: SAP0653 - Tecnologia das Construções II. 2003. p. 28-29, 31-32 Disponível em: $<$ http://www.profwillian.com/sistemas/apostila_fundacoes. pdf $>$. Acesso em: 20 ago.

Pinto, G. P. 2010. O método GPR aplicado à localização de tubulações utilizadas no abastecimento de água na região urbana do município de Belém - Pará. Belém, Dissertação de Pós-Graduação - Geofísica, Universidade Federal do Pará. p. 19-33.

Santos, G. V. 2014. Recalques de Fundação. Patologias devido ao recalque diferencial em fundações, Brasília, Trabalho de Curso - Engenharia Civil, Centro Universitário de Brasília. p. 54-66.

Santos, R. D. dos et al. 2000. Projeto Parque Frei Veloso: levantamento detalhado dos solos campus da llha do Fundão - UFRJ. 2000. Embrapa Solos. Boletim de Pesquisa, n. 19, p. 69. Embrapa Solos, Rio de Janeiro, 2000. 